\title{
Comparative Analysis of Transmission Poles Executed in Mild Steel and High Strength Steel
}

\author{
João SOUSA ${ }^{a}$, Jorge HENRIQUES ${ }^{b}$, Rui BARROS ${ }^{c, *}$ \\ Faculty of Engineering of the University of Porto, Civil Engng Dept, Structural Division, Portugal \\ aec08249@fe.up.pt, bjfmh@fe.up.pt, c, ${ }^{\star}$ rcb@fe.up.pt \\ ${ }^{*}$ Corresponding author
}

Keywords: Transmission Poles, High Strength Steels, Wind, General Method, Costs.

\begin{abstract}
This work aims at modeling and designing a transmission pole structure for further investigation of the economic benefits associated with various grades of steel. Indeed, it was necessary to develop a population of possible design cases, to check structural safety, from which were selected the less expensive solutions. To this end, a computer application was developed that performs the calculation of the wind action on the structure, designs and verifies structural safety automatically and individually for each case (in accordance with the general method of verifying safety against flexural buckling and lateral buckling, present in Eurocode 3 - EC3). An iterative design process yielded 296 viable solutions from which draw the analysis of manufacturing costs. Within this analysis were considered some average prices from which it was possible to calculate the total cost associated with each solution so as to obtain the most economical cases for each steel grade.
\end{abstract}

\section{Introduction}

The objective of this work was part of the master of science dissertation of the first co-author [1] under supervision of the third co-author, consisting in the comparative analysis of the design and production of transmission poles in mild steel and in high strength steel. The analyses are carried out through the modeling and design of several posts with different geometrical characteristics, involving classes of steel from the S235 to the S690. A security check is performed on the overall stability by the general method of verifying the flexural buckling and lateral buckling, according to Chapter 6.3.4 of EC3-1-1 [2].

\section{Structural Steels}

Carbon steels are one of the most important types of structural steels. Despite its essential elements are iron and carbon, these always contain other minor elements which when added to the iron, in conjunction with other treatments, allow to obtain different properties, resistances and/or certain specific characteristics.

The yield stress is a key parameter in the classification and representation of the resistant capacity of a steel. Currently there is a wide range of civil engineering steels whose yield stresses can vary, usually between $235 \mathrm{MPa}$ and $690 \mathrm{MPa}$ (Table 1), to about $1100 \mathrm{MPa}$. Despite its subjective concept, high strength steels are generally regarded as those with a yield stress higher than $500 \mathrm{MPa}[3]$ while mild steels correspond to a lower yield stress. The use of high strength steels has gained over the last years greater commercial interest as it was managed to increase, through technological development, yield strength of steel and their resistant capacities to fracture and weldability, which were greatly reduced formerly [4]. The capabilities of these higher strength steels allow obtaining smaller structural parts and slender sections with smaller footprint and less weight without compromising security. Despite its higher unit price, high strength steels become competitive with mild steels because it is required less amount of material in order to satisfy the same needs (Figure 1). The yield stresses of structural steels from S235 to S460 are addressed in EC3-1-1 while the higher strength steels, from S460 to S700, are treated in EC3-1-12 [5]. 
Tab. 1 Yield Strength According to EC3-1-1 and EC3-1-12 to Thickness Less than $40 \mathrm{~mm}$ and Respective Area of Steel Required to Withstand a Traction Force of 10.000 kN [1]

\begin{tabular}{cccc}
\hline Steel Class & Yield strength according to EC3 $[\mathrm{MPa}]$ & Area required $\left[\mathrm{m}^{2}\right]$ & $\%$ \\
\hline S 235 & 235 & 0,042553 & $+193,61$ \\
\hline S 275 & 275 & 0,036364 & $+150,91$ \\
\hline S 355 & 355 & 0,028169 & $+94,36$ \\
\hline S 450 & 440 & 0,022727 & $+56,81$ \\
\hline S 500 & 500 & 0,020000 & $+38,00$ \\
\hline S 550 & 550 & 0,018182 & $+25,45$ \\
\hline S 620 & 620 & 0,016129 & $+11,29$ \\
\hline S 690 & 690 & 0,014493 & 100 \\
\hline
\end{tabular}

\begin{tabular}{|l|l|l|l|l|l|l|l|l|}
\hline S 690 & S 620 & S 550 & S 500 & S 450 & S 355 & S 275 & S 235 \\
\hline
\end{tabular}

Fig. 1 Thickness Required to Withstand an Axial Load of 10.000kN [1]

However, high strength steels comprise another type of care such as resistance to fragile fracture (tenacity), welding or the exposure to corrosive agents, due to the presence of more slender and thin sections and where there is not a correct protection, may lead to a shorter lifetime of the structure or even a premature structural failure.

\section{Regulatory Actions}

For design process it is considered the action of wind on the structure, calculated in accordance with EC1-1-4 [6], and the action of wind on the transmission cables, obtained by EN 50341-1 [7]. The seismic action is rarely a constraint and involves a different and more complex analysis. It has also been incorporated the effects due to vortex shedding and the security check to ovalling phenomenon.

\section{Basis of Design}

In the project and design of steel structures it is critical to meet the various regulations present in EC3-1-1 (design of steel structures - general rules and rules for buildings). In this particular case, designing a transmission pole in mild and high strength steel, the rules to comply also extend to other more specific bibliographic elements including: EC3-1-5 [8], EC3 -1-10 [9], EC3-1-12 [5] EC3-3-1 [10] EC3-3-2 [11], EN 50341-1 [7], EC8-1 [12] and EC8-6 [13].

The incorporation of second order effects in structural analysis is mandatory according to EC3-3-1 and EN 50341-1. These effects are included in simplified form by increasing the horizontal forces by the expression (1) provided by EC3-1-1:

$$
\frac{1}{1-\frac{1}{\alpha_{c r}}} \text {. }
$$

Moreover, the geometrical imperfections are not considered as the condition that enables its disregard (equation 2), present in the EC3-1-1, verifies in all analysis cases:

$$
\text { Hed } \geq 0,15 \cdot \text { Ved }
$$

In the case of transmission poles, EC3-3-1 and EN 50341-1 together with EC3-1-12 indicate that should be adopted an elastic global analysis in the design and calculation of internal forces. Despite the EN 50341-1 being based on the definitions in EC3-1-1 in the approach to local buckling, it just classifies the cross sections of class 3 or 4 as shown in Figure 2. 
As the class 4 sections involve a reduction of gross area it is employed various area and effective modulus abacus, for the different grades of steel, as presented in the dissertation of Sousa [1]. The verification of the overall stability of the structure is made by the general method of EC 3-1-1 by the equation (3):

$$
\frac{\chi_{o p} \cdot \alpha_{u l t, k}}{\gamma_{M 1}} \geq 1,0
$$

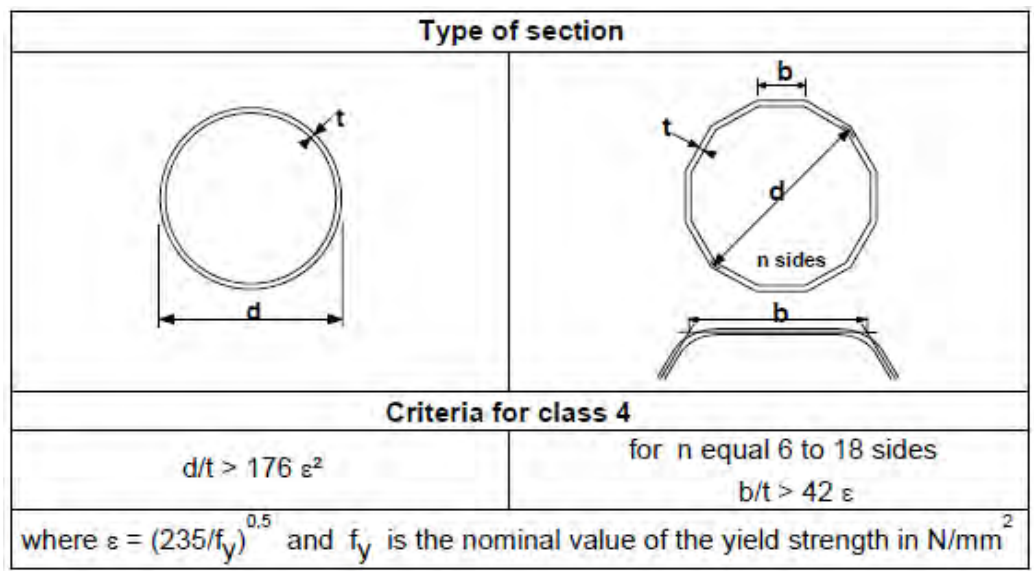

Fig. 2 Classification of Tubular cross Sections Subject to Bending [7]

\section{Design}

In this study it is necessary to design different transmission poles with different sections and geometrical characteristics, different wind and transmission cables actions and different grades of steel. This allows to generate a population of feasible results (poles that check the structural safety) from which can be obtained the most economic and efficient transmission pole, but also produce some comparisons and more relevant results. Due to the large amount of calculation required it has become crucial to develop a method that allows obtaining the wind actions, generalized internal forces and stresses, resistances and safety verification, all automatically and rapidly, for any geometry and mechanical characteristics of the structural pole. Thus it was developed a computer application, performed by Sousa [1], which is based on rules that the Standards EC1-1-4, EC3-1-1, EC3-1-5, EC3-1-12, EC3-3-1 and EN 50341-1 advocate. The location of the analyzed poles corresponds to a terrain within zone B and category 0 , according with the characteristics of EC1-1-4. In geometric terms each structure comprises a pyramidal tower with a height of $46.5 \mathrm{~m}$ whose stem is formed by tubular metal sheets that may have a tapered polygonal section with $8,12,16$ and 20 faces, and can be made by various different classes of steel from S235 to S690. Due to transportation it was necessary to split the post into 5 parts: 4 modules with a height of $10 \mathrm{~m}$ (to take into account possible connections by slip-joints) and one with $6.5 \mathrm{~m}$. At the top of the structure there are eight arms for the installation of transmission cables arranged symmetrically relative to the axis of the pole: two arms to guard cables at $46.5 \mathrm{~m}$ and six adjacent arms for transmission cables, placed in pairs at heights of $22.5 \mathrm{~m}, 32.5 \mathrm{~m}$ and $42.5 \mathrm{~m}$. As constraints, were considered: the plate thicknesses in each module, ranging from $3 \mathrm{~mm}$ to $20 \mathrm{~mm}$; the base section diameter, ranging from $1800 \mathrm{~mm}$ up to a minimum limited by the security check; and, the top diameters of $200 \mathrm{~mm}, 350 \mathrm{~mm}$ and $500 \mathrm{~mm}$ in order to obtain the most efficient inclinations.

Within the calculation of internal forces for the ultimate limit state, it is considered an increase of $10 \%$ on self-weight action, $40 \%$ in the wind action on the structure and $100 \%$ in the transmission cables actions. As the rules applying to the serviceability limit state are not defined by any standard, they are not being considered. With these criteria, after a whole iterative design process, it appears that the minimum base diameter that allows the execution of a transmission pole without compromising security is $1300 \mathrm{~mm}$ for S690 steel. On the other hand, S235 and S275 steels cannot ensure the security for a base diameter of $1800 \mathrm{~mm}$ (initial limitation) which are therefore excluded 
from the population analysis. At the end of this procedure were recorded 296 viable solutions, for the design of the transmission poles that check security and global stability.

\section{Cost Analysis}

In order to perform an analysis of manufacturing costs and to obtain the most economical solution it is necessary to examine some of the basic costs associated with the production of a transmission pole. Sousa [1] considered some average prices according to the steel grade, used cross-sectional geometry, welding, galvanizing and final painting.

The price of steel is highly variable over time and depends on various parameters such as market demand, ordered quantities and prices of raw materials. The prices considered are in Table 2.

Tab. 2 Average Prices Used for Each Class of Steel [1]

\begin{tabular}{ccc}
\hline Steel class & Price $[€ /$ Ton $]$ & $\%$ \\
\hline S 355 & 650 & 100 \\
\hline S 450 & 720 & $+10,8$ \\
\hline S 500 & 750 & $+15,4$ \\
\hline S 550 & 775 & $+19,2$ \\
\hline S 620 & 810 & $+24,6$ \\
\hline S 690 & 840 & $+29,2$ \\
\hline
\end{tabular}

As it is employed a polygonal cross-section with larger number of faces, the greater the cost of manufacture. The main factor influencing this parameter is the bending process in which the steel plates are bended in order to obtain the desired cross-section. It is considered necessary 4 minutes per wedge corner bending at a price of $85 € / \mathrm{h}$ (Table 3 ).

Tab.3 Bending Prices [1]

\begin{tabular}{ccccc}
\hline Number of bends & Working time $[\mathrm{min}]$ & Price per module & $\%$ & Price for 5 modules \\
\hline 8 & 32 & $45,3 €$ & 100 & $227 €$ \\
\hline 12 & 48 & $68,0 €$ & +50 & $340 €$ \\
\hline 16 & 64 & $90,7 €$ & +100 & $453 €$ \\
\hline 20 & 80 & $113,0 €$ & +150 & $567 €$ \\
\hline
\end{tabular}

To complete the construction of cross sections it is necessary to make longitudinal welds in each module of the pole. If this has a base diameter superior to $400 \mathrm{~mm}$ the welding is bilateral and is performed by a robot at a rate of $2,5 \mathrm{~min} / \mathrm{m}$ at an average price of $110 € / \mathrm{h}$. Otherwise the solder is unilateral and is performed manually at a speed of $50 \mathrm{~min} / \mathrm{m}$ at an average price of $80 € / \mathrm{h}$ (Table 4).

Tab.4 Welding Prices [1]

\begin{tabular}{ccc}
\hline Case & Working time [min] & Welding price \\
\hline 1 Module of 10m welded 2x by robot & 50 & $92 €$ \\
\hline 1 Modulo of 6,5m welded 1x manually & 325 & $433 €$ \\
\hline $\begin{array}{c}\text { 4 Modules of 10m welded by robot and 1 module of } \\
\text { 6,5m welded manually }\end{array}$ & $200+325$ \\
\hline $\begin{array}{c}\text { 4 Modules of 10m and 1 module of 6,5m welded by } \\
\text { robot }\end{array}$ & 232 & $426 €$
\end{tabular}

To ensure the longevity of the steel plates of the cross sections it is applied an anti-corrosive treatment by hot dip galvanizing. For this process it is considered an average cost of $450 € /$ ton of steel. After this process it is initiated the external paintwork in order to ensure that the external appearance is the required or desired by the contract. The average price considered for this activity is $24 € / \mathrm{m}^{2}$ of area to paint.

Within the manufacture of a transmission pole there are still other related costs that are not considered in this analysis such as the price of drilling, assembly prices and prices of internal drives. 
These values are not taken into account as they have little variability among the design possibilities obtained and are less relevant to the overall price. In the same situation, as the conductors cable's arms are similar in all cases analyzed, the costs of manufacturing were not included in the study. The remaining costs associated with transportation, installation and maintenance were also not considered in the analysis.

Based on these prices it was possible to make an estimate of the cost of manufacture of each event within the 296 possibilities of design previously obtained for the transmission poles studied. Thus, the more economical cases can be compared in order to analyze possible savings in the use of a particular class of steel. Indeed, Table 5 and Figure 3 presents a summary of the final prices obtained.

Tab. 5 Summary of Prices for the Most Economical Solutions [1]

\begin{tabular}{ccc}
\hline Steel class & Minimum manufacture price & $\%$ \\
\hline S 355 & $24.417,9 €$ & $+30,2$ \\
\hline S 450 & $22.272,2 €$ & $+18,8$ \\
\hline S 500 & $20.617,3 €$ & $+10,0$ \\
\hline S 550 & $19.797,6 €$ & $+5,6$ \\
\hline S 620 & $19.301,0 €$ & $+3,0$ \\
\hline S 690 & $18.747,1 €$ & 100 \\
\hline
\end{tabular}

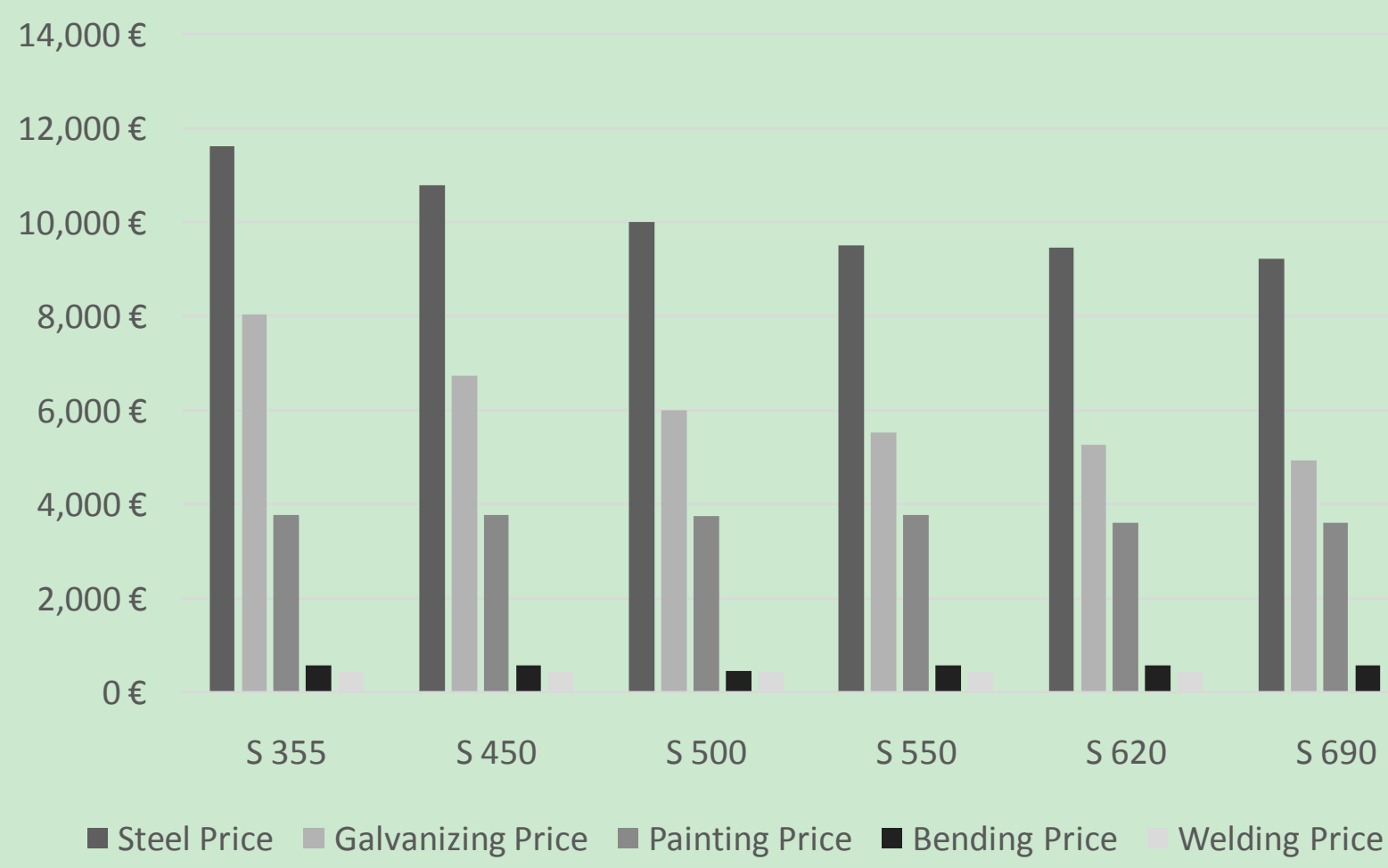

Fig. 3 Discretization of Prices within the Most Economical Solution for Each Class of Steel [1]

\section{Conclusion}

The constant demand for less expensive structural solutions in the market meant that transmission lines supports, lattice towers or poles, were subjected to further structural analysis in order to better understand the influence of the use of high strength steels in its behavior and economy. Thus, the present study [1] was carried out in the form of a comparative analysis for a more particular case of transmission poles in order to ascertain the existence of advantages associated with high strength steels. Indeed, the results obtained from this study indicate a monetary savings of $3.0 \%, 5.6 \%, 10.0 \%$, $18.8 \%$ and $30.2 \%$ in the cost of manufacturing a steel pole in S690 compared to steel S620, S550, $\mathrm{S} 500, \mathrm{~S} 450$ and S355 respectively. The parameters that more influence the price of production 
correspond to the volume of steel used and the galvanizing process, which directly depends on the weight of the structural component.

It was concluded that the choice of high strength steels allows to obtain lower prices not only in the manufacture of transmission poles but also have a direct and beneficial influence on transportation and installation due to the presence of less bulky and lighter components.

\section{Acknowledgement}

The authors acknowledge the support from the project "VHSSPOLES - Very High Strength Steel

Poles" (Faculty of Engineering of the University of Porto, reference 21518).

\section{References}

[1]Sousa, J.P.P.d., Comparative Analysis of Transmission Poles Executed in Mild Steel and High Strength Steel 2014, Master of Science dissertation (in Portuguese), Faculty of Engineering of the University of Porto: Porto.

[2]EN 1993-1-1: Eurocode 3: Design of steel structures - Part 1-1: General rules for buildings 2010, European Committee for Standardization (CEN): Brussels.

[3]Billingham, J., et al., Review of the performance of high strength steels used offshore. Health Saf. Exec, 2003. 105.

[4]Schröter, F., Trends of using high-strength steel for heavy steel structures. MA Giejowski, A. Kozowski, L. lczka, J. Zióko (Hrsg.): Progress in Steel, Composite and Aluminium Structures, S: p. 292-293.

[5]EN 1993-1-12: Eurocode 3: Design of steel structures - Part 1-12: Additional rules for the extension of EN 1993 up to steel grades S700.2007, European Committee for Standardization (CEN): Brussels.

[6]EN 1991-1-4: Eurocode 1: Actions on structures - Part 1-4: Wind actions. 2010, European Committee for Standardization (CEN): Brussels.

[7]EN 50341: Overhead electrical lines exceeding AC $45 \mathrm{kV}$ - Part 1: General requirements Common specifications. 2001, European Committee for Electrotechnical Standardization (CENELEC): Brussels.

[8]EN 1993-1-5: Eurocode 3: design of steel structures - Part 1-5: Plated structural elements. 2006, European Committee for Standardization (CEN): Brussels.

[9]EN 1993-1-10: Eurocode 3: Design of steel structures - Part 1-10: Material toughness and through-thickness properties. 2005, European Committee for Standardization (CEN): Brussels.

[10]EN 1993-3-1: Eurocode 3: Design of steel structures - Part 3-1: Towers, masts and chimneys Towers and masts. 2006, European Committee for Standardization (CEN): Brussels.

[11]EN 1993-3-2: Eurocode 3: Design of steel structures - Part 3-2: Towers, masts and chimneys Chimneys. 2006, European Committee for Standardization (CEN): Brussels.

[12]EN 1998-1: Eurocode 8: Design of structures for earthquake resistance - Part 1: General rules, seismic actions and rules for buildings. 2004, European Committee for Standardization (CEN): Brussels.

[13]EN 1998-6: Eurocode 8: Design of structures for earthquake resistance - Part 6: Towers, masts and chimneys. 2005, European Committee for Standardization (CEN): Brussels. 